\title{
Estado de ocupação das margens do Rio Macacu - Rio de Janeiro (Brasil): diagnóstico preliminar
}

\author{
Guilherme de Assis Rodrigues ${ }^{1}$ (D) \& Gisa Eneida Marques Machado ${ }^{2}$
}

(1) ONG Guardiões do Mar, Rua Alfredo Azamor 739, Boa Vista 24466-000, São Gonçalo, Rio de Janeiro, Brasil. E-mail: guilhermeassisrj@yahoo.com.br

(2) Faculdades Integradas Maria Thereza, Av. Visconde do Rio Branco 869, São Domingos 24210-006, Niterói, Rio de Janeiro, Brasil. E-mail: gisaeneida@gmail.com

Rodrigues G.A. \& Machado G.E.M. (2020) Estado de ocupação das margens do Rio Macacu - Rio de Janeiro (Brasil): diagnóstico preliminar. Pesquisa e Ensino em Ciências Exatas e da Natureza, 4: e1423. http://dx.doi.org/10.29215/pecen.v4i0.1423

Editor acadêmico: José Deomar de Souza Barros. Recebido: 15 janeiro 2020. Aceito: 08 junho 2020. Publicado: 11 junho 2020.

Resumo: O estudo de bacias hidrográficas mostra-se cada vez mais necessário na correlação com as Áreas de Preservação Permanente (APP), pois a existência de conflitos entre uso e ocupação e o descumprimento da legislação nessas áreas põem em risco a integridade dos recursos hídricos, afetando a qualidade da água. O diagnóstico ambiental das condições in loco é o primeiro passo para o planejamento de uso sustentável de uma bacia hidrográfica, possibilitando identificar os fatores que possam estar interferindo e provocando a degradação. O objetivo deste trabalho foi realizar o diagnóstico ambiental em campo da Bacia Hidrográfica do Rio Macacu e avaliar os principais impactos ambientais das suas margens, propondo medidas para a correção dos problemas. Na área do Baixo Macacu, foi constatada a implementação de áreas agrícolas sem o manejo adequado e a ausência de matas ciliares. Já no Alto Macacu, a ausência de planejamento urbano favoreceu a ocupação das áreas de APP ao longo do leito do rio, principalmente por residências, que lançam o esgoto in natura, contribuindo para a degradação do curso d'água. Ao final, são apresentadas são apresentadas propostas para correção dos problemas encontrados.

Palavras chave: Bacia hidrográfica, erosão, mata ciliar, poluição.

\section{Occupation status of the banks of the Macacu River - Rio de Janeiro (Brazil): preliminary diagnosis}

Abstract: The study of hydrographic basins has become increasingly necessary in the correlation with Permanent Protection Areas (PPA), since the existence of conflicts between use and occupation and the non-compliance with legislation in these areas endanger the integrity of water resources, affecting water quality. The environmental diagnosis of onsite conditions is the first step in planning the sustainable use of a watershed, making it possible to identify the factors that may be interfering and causing degradation. The objective of this work was to perform the environmental diagnosis in field of the Macacu River Basin and evaluate the main environmental impacts of its margins, proposing measures to correct the problems. In Baixo Macacu, the implementation of agricultural areas without proper management and the absence of riparian forests were found. In Alto Macacu the absence of urban planning favored the occupation of PPA areas along the riverbed, mainly by residences, which release sewage in natura, contributing to the degradation of the watercourse. At the end, proposals are presented to correct the problems encountered.

Key words: Hydrographic basin, erosion, riparian forest, pollution.

\section{Introdução}

No Brasil, as Áreas de Preservação Permanente (APPs) são ambientes protegidos por lei e têm a função ambiental de proteger os recursos hídricos, a paisagem, a geologia, o solo e a biodiversidade local, além de oferecer sustento e bem-estar à população humana (Colpo et al. 2009). De maneira geral, as APPs possuem importância para a estabilidade dos ambientes, principalmente por agregar serviços ecossistêmicos fundamentais (Kominoski et al. 2013). Em 
áreas com cobertura florestal nativa, a vegetação protege o solo contra erosão, assoreamento e lixiviação excessiva de nutrientes. Dessa forma, as APPs às margens de cursos d'água são muito importantes na manutenção da quantidade e qualidade do suprimento de água (Morgan 2005).

Sob a ótica da hidrologia florestal, as matas ciliares ocupam as áreas mais dinâmicas da paisagem, tanto em termos hidrológicos, como ecológicos e geomorfológicos. Estas áreas têm sido chamadas de "zonas ripárias". As funções desempenhadas pelas zonas ripárias são: frear o escoamento das águas para o curso d'água, filtrar sedimentos e resíduos líquidos e sólidos, dar estabilidade às margens por meio das raízes e preservar a rugosidade das margens (Lima 2008).

Contudo, o processo de ocupação do território brasileiro é marcado, historicamente, pela intensa exploração de seus recursos naturais e supressão da vegetação nativa, desconsiderando sua importância ambiental e a sustentabilidade. Impactos antrópicos, com destaque para a agropecuária e expansão da urbanização, foram responsáveis por diversos problemas ambientais em nosso país (Pereira et al. 2016). Essas ações modificam a dinâmica hidrológica em razão das alterações nas características de cobertura e perfil do solo, podendo ocasionar prejuízos diversos, como intensificação da erosão, redução da qualidade dos solos, assoreamento e enchentes (Coutinho et al. 2013). Ademais, tais pressões impostas ao sistema solo-planta-água impactam o ciclo hidrológico, gerando incertezas na manutenção sustentável das bacias hidrográficas (Lyra \& Rigo 2019). Além disso, a maior parte da população brasileira está concentrada em cidades próximas aos rios e mananciais, desencadeando impactos negativos nos recursos hídricos. Problemas com poluição, proliferação de vetores, a falta de tratamento dos resíduos doméstico e industrial, desmatamento de matas ciliares e do uso inadequado de agrotóxicos e fertilizantes são alguns dos exemplos (Maia 2002; Galindo 2004).

O estudo de bacias hidrográficas mostra-se cada vez mais necessário na correlação com as APPs, pois, a existência de conflitos entre uso e ocupação e o descumprimento da legislação nessas áreas, põem em risco a integridade dos recursos hídricos, afetando a qualidade da água, devido à dinâmica fluvial e ao escoamento superficial da água ao longo da bacia de drenagem (Pires et al. 2012; Santos et al. 2015). O diagnóstico ambiental das condições in loco é o primeiro passo para o planejamento de uso sustentável de uma bacia hidrográfica, possibilitando identificar os fatores que possam estar interferindo e provocando a degradação (Gomes et al. 2018). Este trabalho teve como objetivo realizar o diagnóstico ambiental em campo da Bacia Hidrográfica do Rio Macacu e avaliar os principais impactos ambientais das suas margens, propondo medidas para a correção dos problemas.

\section{Metodologia}

\section{Caracterização da área de estudo}

A Bacia do Rio Macacu está presente na Região Metropolitana do Rio de Janeiro e é abrangida pelos Municípios de Cachoeiras de Macacu, Guapimirim e Itaboraí (Figura 1). O Rio Macacu nasce na Serra dos Órgãos, dentro dos limites do Parque Estadual dos Três Picos, em relevo escarpado, a uma altitude de aproximadamente $1.700 \mathrm{~m}$, no município de Cachoeiras do Macacu - RJ (Ecologus-Agrar 2003; Hora et al. 2010). Já sua foz, localiza-se na Baía de Guanabara, especificamente na Área de Proteção Ambiental de Guapi-Mirim (APA), Unidade de Conservação que abriga um dos últimos redutos contínuos de Manguezal do Estado do Rio de Janeiro (Figura 2).

A região hidrográfica estudada corresponde aproximadamente a $31 \%$ do total da área continental de contribuição da Baía de Guanabara e é responsável pelo abastecimento de cerca de 2.5 milhões de habitantes dos municípios de Cachoeiras de Macacu, Guapimirm, Itaboraí, São Gonçalo e Niterói, além de ser utilizada para irrigação e piscicultura (Roberto 2009; Hora et al. 2010).

\section{Contextualização do problema}

O Projeto UÇÁ, projeto realizado pela ONG Guardiões do Mar por meio do Patrocínio Petrobras (Petróleo Brasileiro S.A.), realiza a Operação LIMPAOCA desde 2014, na foz do Rio Macacu. A Operação conta com a participação de lideranças pesqueiras locais (Associação de 
Catadores e Pescadores de Itambí/Itaboraí (ACAPESCA)) e a Associação de Catadores do Município de Magé (ACAMM). Essa atividade desenvolve um serviço ambiental (limpeza de manguezal) e um serviço socioeconômico (com geração de renda alternativa para catadores de caranguejo e/ou pescadores), tendo como recurso pesqueiro principal o caranguejo, além de alinhar-se, também, com Políticas Públicas. Com o objetivo de contribuir com a renda dos catadores, essa operação ocorre nos períodos de Defeso do Uçá - Ucides cordatus (Linnaeus, 1763), atendendo à legislação ambiental pertinente (Decreto Lei no 221/1967 e Portaria IBAMA $\left.\mathrm{n}^{\mathrm{o}} 124 / 2002\right)$.

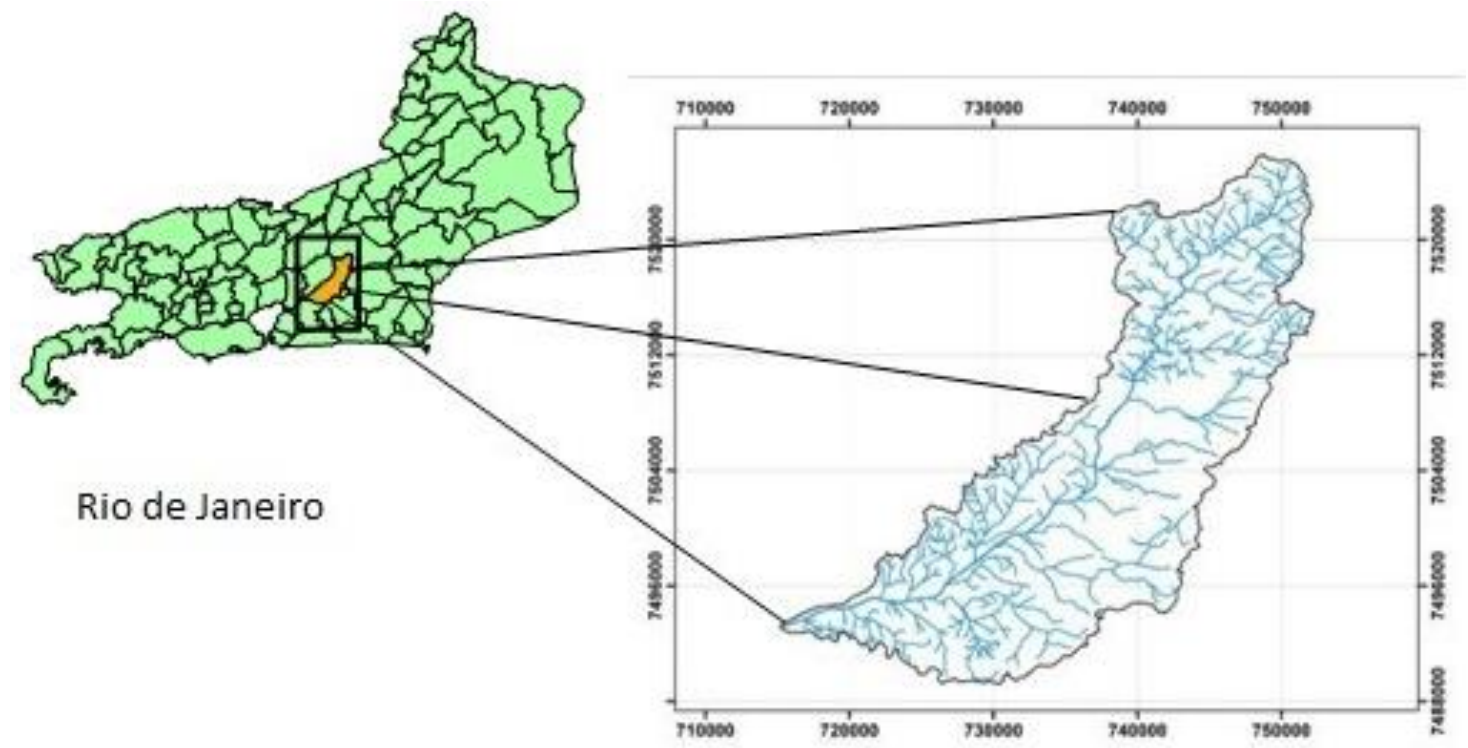

Figura 1. Estado do Rio de Janeiro, com destaque para o município de Cachoeiras de Macacu.

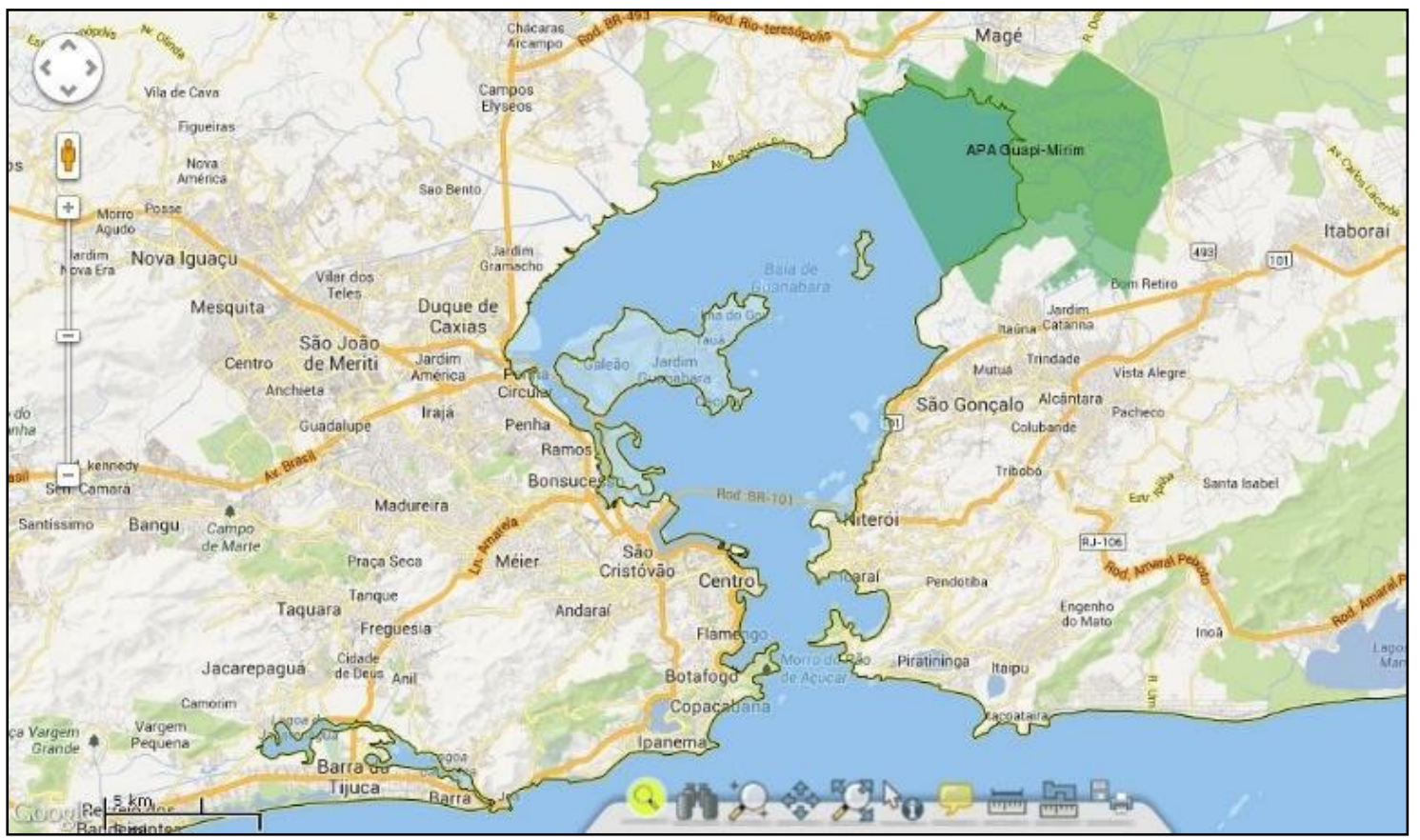

Figura 2. Baia de Guanabara com destaque para a área da APA de Guapi-Mirim na porção leste. Fonte: ICMBio (2020).

Em 4.0 hectares (ha), foram removidos até dezembro de 2019, aproximadamente 21 toneladas de resíduos sólidos. Esse resultado é apenas uma pequena amostra do que se expressa nos 6.200 ha de manguezais localizados no fundo da Baía de Guanabara. Além de todo o resíduo sólido encontrado, durante as atividades foi observado um acelerado processo de assoreamento 
de áreas localizadas na foz de diversos rios que abastecem o fundo da Baía de Guanabara, incluindo o Rio Macacu. O Instituto Baía de Guanabara identifica a baía como um estuário de inúmeros rios que descarregam mais de $200 \mathrm{mil} \mathrm{l} / \mathrm{s}$ de água $\left(200 \mathrm{~m}^{3} / \mathrm{s}\right)$ de uma bacia hidrográfica de $4080 \mathrm{~km}^{2}$ (Roberto 2009). Amador (2012) aponta os principais rios tributários da Baía de Guanabara escoando, juntos, $356.8 \mathrm{~m}^{3} / \mathrm{s}$ de água doce na Baía de Guanabara (Tabela 1).

Nesse contexto, o Rio Macacu se apresenta como importante contribuinte na área de atuação do Projeto UÇÁ.

Tabela 1. Média de escoamento de águas doces dos principais rios tributários da Baía de Guanabara (Amador 2012).

\begin{tabular}{cc}
\hline Principais Rios & Medias $\left(\mathrm{m}^{\mathbf{3}} / \mathbf{s}\right)$ \\
\hline Caceribu & 128.5 \\
Macacu & 115.7 \\
Iguaçu & 72.0 \\
Saracuruna & 23.1 \\
Suruí & 5.9 \\
Urbanbasins & 4.8 \\
Canal de Magé & 4.0 \\
Iriri & 2.8 \\
\hline Total & $\mathbf{3 5 6 . 8}$ \\
\hline
\end{tabular}

\section{Diagnóstico das margens do Rio Macacu}

O diagnóstico do Rio Macacu foi realizado pelos analistas ambientais do Projeto UÇÁ de março a novembro de 2019 e contou com auxílio de um drone modelo Dji Phanton Standard3. O trabalho foi dividido em duas frentes: o Baixo Macacu - porção navegável do Rio Macacu, e o Alto Macacu - porção não navegável (Figura 3). No trecho do Baixo Macacu, a navegação foi feita em lancha metálica (motor de $25 \mathrm{Hp}$.), com capacidade para 4 pessoas (Figura 4). A equipe saiu do interior da APA de Guapi-Mirim e navegou em direção à nascente do rio, perfazendo todo trecho navegável. A partir do ponto onde a navegação se tornou impossibilitada em razão da baixa profundidade, causada pelo assoreamento do rio, foi iniciada a segunda frente (Alto Macacu), que foi realizada por meio de veículos a partir da localidade de Papucaia.

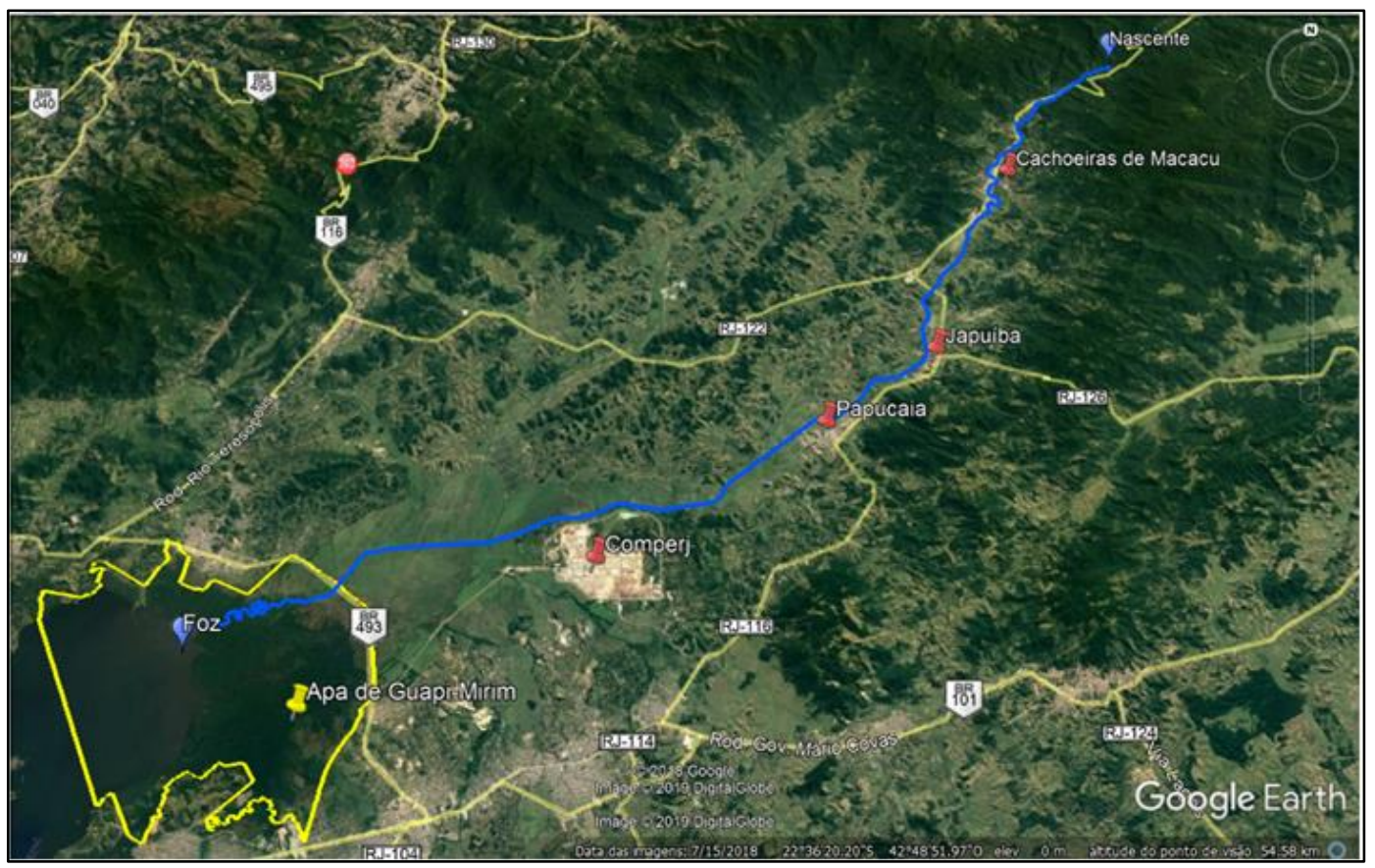

Figura 3. Detalhamento de todo o curso do Rio Macacu, em azul. Em amarelo, a APA de Guapi-Mirim, onde se localiza a foz do rio, na Baía de Guanabara. Destaque para as locais como Papucaia, Japuíba, Cachoeiras de Macacu e a nascente do rio. (Fonte: Google Earth Pro). 


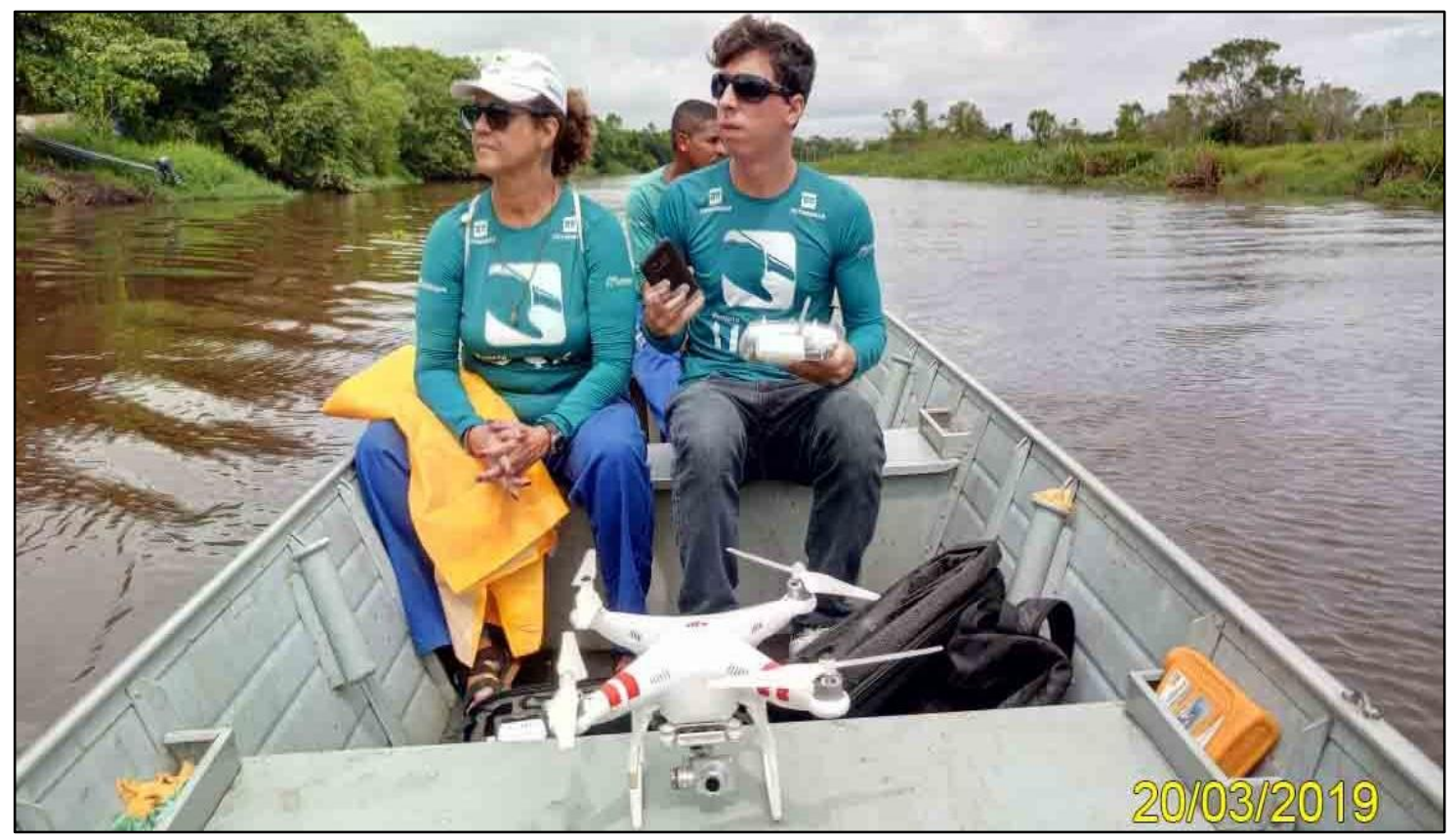

Figura 4. Equipe do Projeto UÇÁ em embarcação realizando o diagnóstico das margens do Rio Macacu (Fonte: Projeto UÇÁ).

\section{Resultados e Discussão}

\section{Baixo Macacu}

O trecho navegável de diagnóstico ambiental foi de $40.0 \mathrm{Km}$ até o Bairro Papucaia, localizado no município de Cachoeiras do Macacu - RJ. A distância percorrida compreende $57.1 \%$ de toda extensão do rio.

Foi constatado severo grau de degradação das margens, predominando a ausência de mata ciliar, havendo apenas pastagens abandonadas formadas pelas espécies Panicum maximum Jacq. e Melinis minutiflora P. Beauv. (Figuras 5), gramíneas usadas como forrageamento para gado, popularmente conhecidas como "capim-massai" e "capim-gordura", respectivamente (Brasil 2001; Martins et al. 2004). No percurso avaliado também foram constantes a ocorrência de processos erosivos nas margens, o que favorece a perda de solo. Assim, a retirada da vegetação e a exposição do solo à ação direta das chuvas causam perdas elevadas de solo e de água, além de alterações em suas propriedades físicas e químicas (Carvalho et al. 2005).

A espécie Panicum maximum é apontada por Mantoani et al. (2012) como uma das responsáveis por perdas anuais consideráveis na biodiversidade dos ecossistemas naturais, causando sérios problemas à conservação, levando muitas espécies à extinção local, podendo ser uma espécie de barreira para o estabelecimento de espécies nativas. Já Melinis minutiflora é uma gramínea de origem africana, introduzida em países tropicais como forrageira, atualmente, considerada como espécie naturalizada (exótica estabelecida). Essa gramínea está adaptada à condição de baixa fertilidade do solo (Martins et al. 2004). Segundo Mielke et al. (2015), as ações antrópicas são as principais responsáveis pelo surgimento de condições favoráveis ao estabelecimento de espécies invasoras. Além disso, o uso excessivo dos recursos naturais diminui efetivamente a diversidade natural do ecossistema invadido e é um dos principais fatores que contribui para o estabelecimento de espécies exóticas (Zanchetta \& Diniz 2006).

$\mathrm{Na}$ área do Baixo Macacu, a implementação de áreas agrícolas foi realizada sem o manejo adequado, ficando marcada pela presença de fazendas de gado bovino (Figura 6), onde, constantemente, são avistados animais na beira do rio, ambiente que dispõe de forragem e condições de conforto térmico proporcionado pela proximidade da água. Contudo, esta prática é geomorfologicamente preocupante, pois acaba levando à degradação das margens, uma vez que influenciam nos processos erosivos, alterando a paisagem e resultando em efeitos de ordem 
direta e indireta (Thomaz \& Dias 2007, 2009). Esse efeito é potencializado quando há remoção da mata ciliar, pois o solo fica exposto aos processos erosivos, levando a um acelerado efeito de assoreamento dos cursos d'água (Casseti 1983; Thomaz \& Dias 2007). Além disso, a ausência da vegetação favorece a entrada de material particulado, que se direciona para o curso do rio por meio do escoamento superficial, o que afeta a disponibilidade de água em quantidade e qualidade (Castro et al. 2013). Essa condição das margens leva à ausência de atributos físicos e químicos que permitam a colonização vegetal espontânea do ambiente (Valcarcel \& D’Alterio 1998).

A

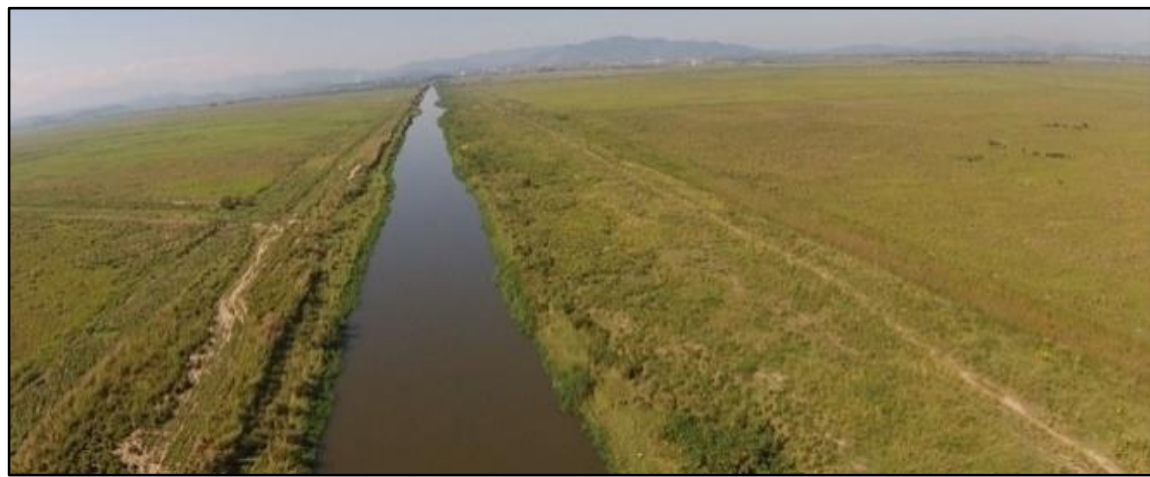

B
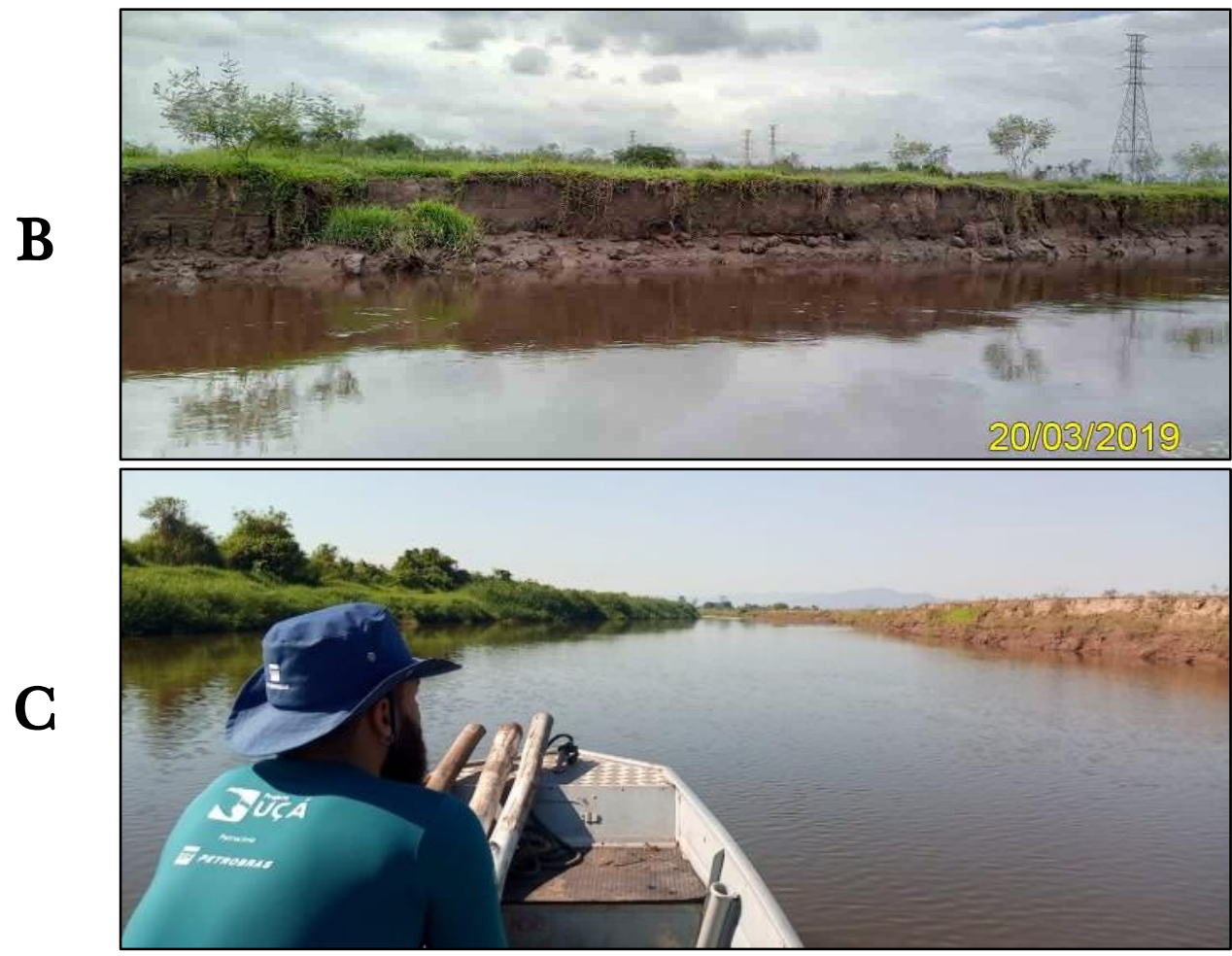

D

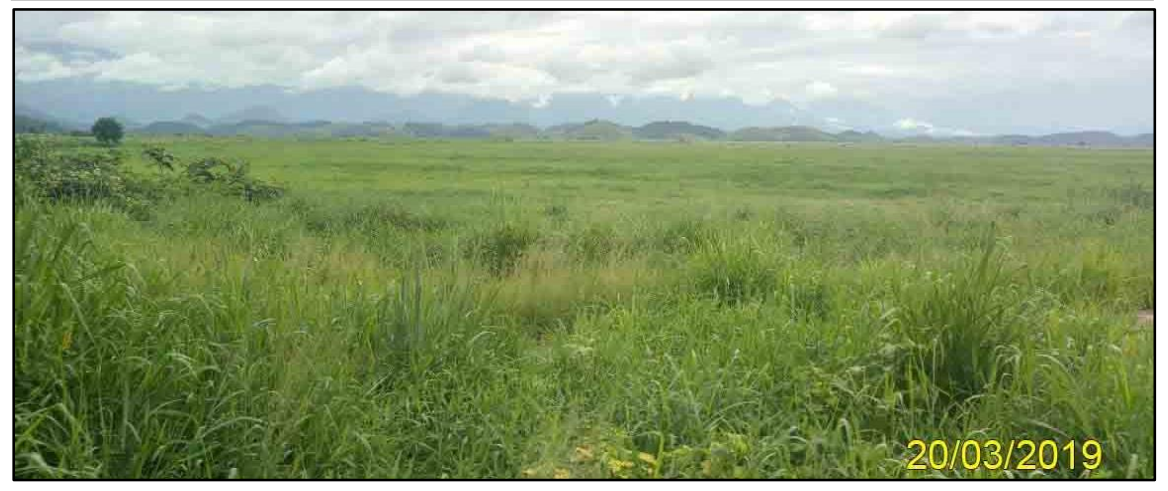

Figura 5. Grau severo de degradação das margens do Rio Macacu: A. Imagem aérea obtida por drone evidenciando a ausência de mata ciliar; B-C. Detalhamento dos processos erosivos nas margens do rio; D. Área de APP dominada por Panicum maximum (Fonte das imagens: Projeto UÇÁ). 


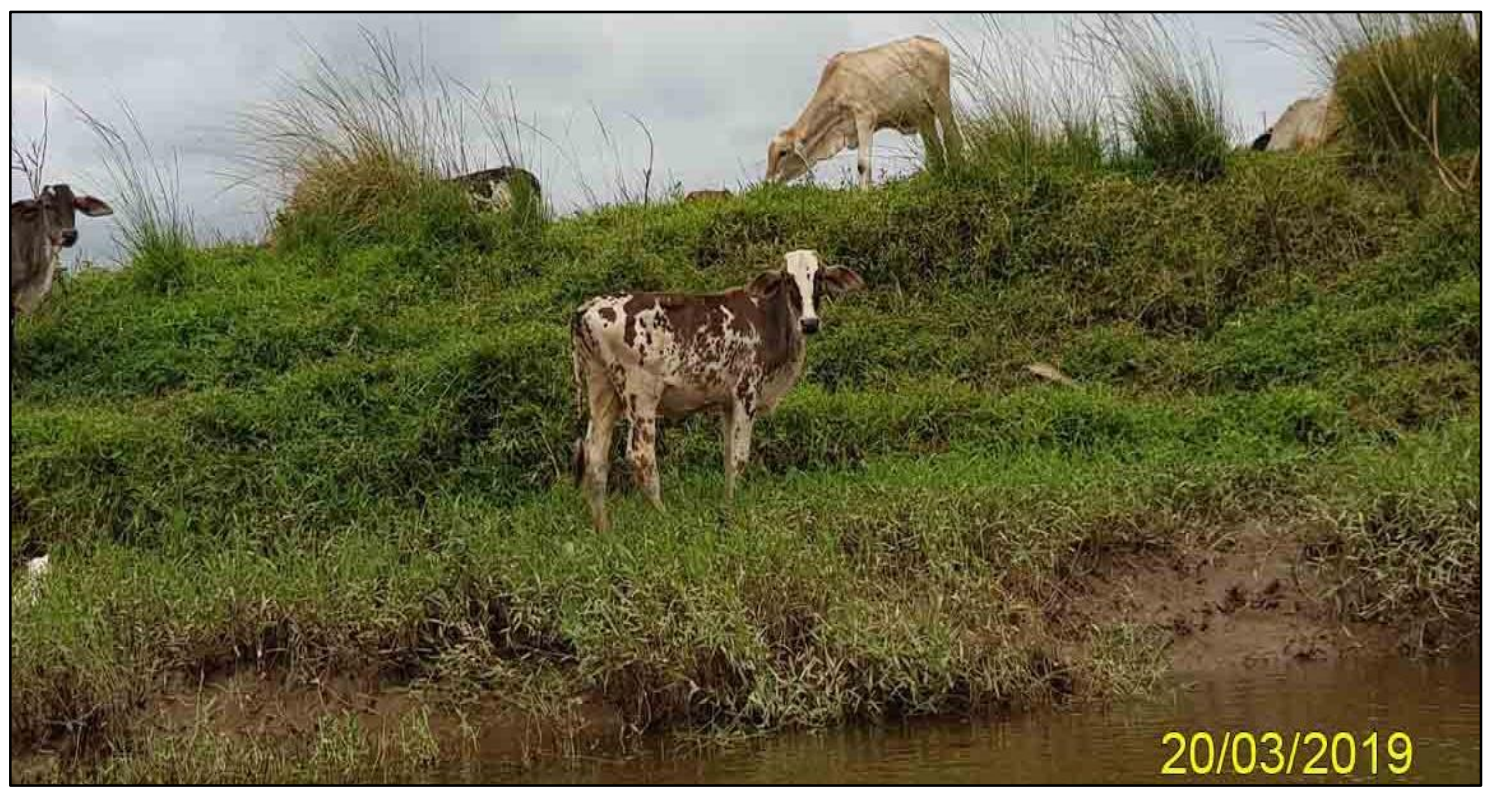

Figura 6. Intenso pastoreio de animais às margens do rio Macacu (Fonte: Projeto UÇÁ).

De acordo com Tucci \& Clarke (1997), a erosão do solo é agravada quando sua superfície se torna desprotegida sofrendo a ação do impacto da gota de chuva, que ocasiona selamento superficial do solo. Este selamento diminui drasticamente a infiltração e acelera o escoamento superficial. Por outro lado, a capacidade de infiltração dos solos com a presença de vegetação é alta, diminuindo o escoamento superficial, que é um dos maiores causadores de erosão hídrica (Silva et al. 2011). Em um estudo na Bacia do Rio Guandu, Região Metropolitana do Rio de Janeiro, Salamene et al. (2011) declaram que somente a criação de leis e decretos não garante a preservação de matas ciliares, uma vez que a presença de áreas antropizadas, em detrimento da área de vegetação natural nas APP, mostra o descumprimento da legislação vigente. Essa condição foi também verificada na Bacia do Rio Macacu.

Segundo Lima \& Zakia (2004), a mata ciliar é de extrema importância para a manutenção dos ecossistemas aquáticos, pois auxilia na infiltração de água no solo, facilita o abastecimento do lençol freático, mantêm a qualidade da água e dificulta o escoamento superficial de partículas e sedimentos que causam poluição e assoreamento dos recursos hídricos. Ainda segundo esses autores, essas matas fornecem sombra mantendo a estabilidade térmica da água, protegem contra o impacto direto da chuva no solo, minimizam os processos erosivos e servem de abrigo e alimento para grande parte da fauna. Assim, a presença da mata ciliar aumenta a rugosidade da superfície da bacia e o tempo de permanência da água na superfície do solo, aumentando sua infiltração (Bertoni \& Lombardi Neto 2010).

\section{Alto Macacu}

Na região do Alto Macacu, localizada no perímetro urbano de Cachoeiras de Macacu, as áreas de APP ao longo do leito do rio estão ocupadas irregularmente, principalmente por residências, que lançam o esgoto in natura nos corpos d'água, contribuindo para o acúmulo de resíduos ao longo do rio (Figura 7). Assim, as referidas ocupações têm relação direta com a baixa qualidade das águas.

Segundo Andrade \& Romero (2006), na maioria das cidades brasileiras, as ocupações irregulares, como as encontradas, ocorrem não por falta de normas, pois a legislação ambiental brasileira é bastante rigorosa, mas pela sua não aplicação por parte dos agentes públicos, pelo desconhecimento técnico, pela corrupção no trato dessas questões e pela inviabilidade de algumas ações diante de situações sociais incontroláveis. Assim, a ocupação irregular, além de limitar os habitats naturais das espécies e causar a extinção destas, acarreta a contaminação da rede hidrográfica por lixo, esgoto doméstico e outros insumos (Silva et al. 2011) que irão percorrer todo o rio até chegarem nos manguezais da Baía de Guanabara. Vale destacar que 
lançamento de efluentes domésticos diretamente no rio tem severos impactos ambientais, como a poluição do solo, a contaminação das águas superficiais e subterrâneas, que podem apresentar elevados níveis de coliformes fecais, constituindo um perigoso foco de disseminação de doenças, como a esquistossomose, febre tifoide, diarreias e disenterias bacterianas, como cólera (Heller \& Möller 1995). Conforme a Companhia de Saneamento de Minas Gerais (COPASA 2015), o excesso de efluentes domésticos causa assoreamento e diminui o nível de oxigênio nos rios, colocando em risco a vida aquática e de todos que dependem dela. Dessa forma, a qualidade da água de uma bacia é uma resultante direta do uso e da ocupação do solo (Vanzela et al. 2010).
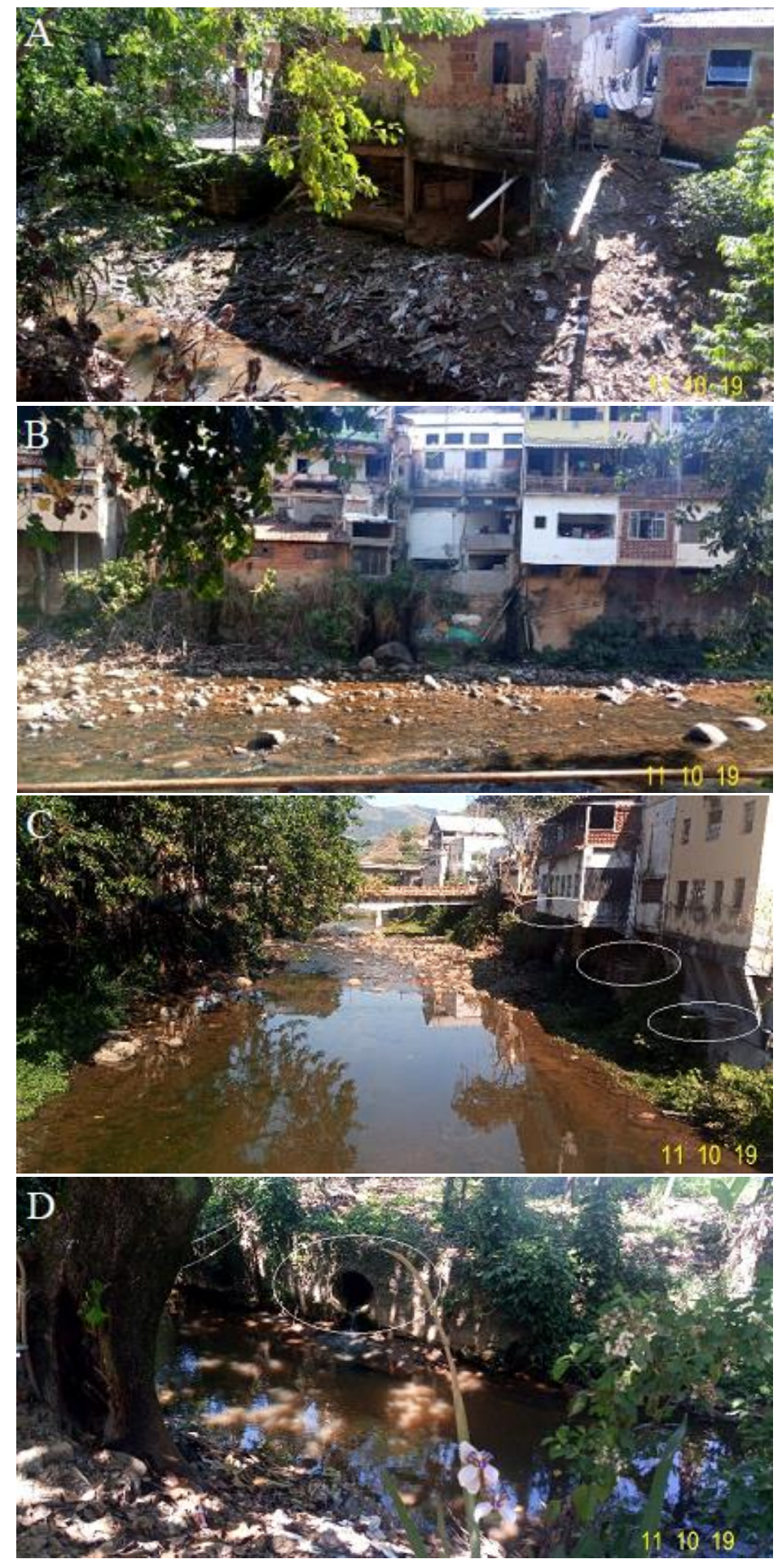

Figura 7. Ocupação irregular da região do Alto Macacu no perímetro urbano de Cachoeiras de Macacu: A. Presença de casas e resíduo de construção as margens da porção alta do rio Macacu; B. Despejo de esgoto doméstico in natura nas águas do rio Macacu (círculos brancos); C. Despejo de esgoto por manilha, nas águas do rio Macacu; D. Evidências da pressão de alterações das margens do rio (Fonte das imagens: Projeto UÇÁ). 
Por promover a saúde e a prevenção de doenças, os investimentos nos serviços de saneamento auxiliam na diminuição dos gastos públicos com a saúde, além de ter impacto sobre a capacidade produtiva de cada indivíduo e o desenvolvimento da região (Silva \& Esperidião 2017). Contudo, mesmo a questão de saneamento básico possuindo vultosa importância, a equipe do Projeto UÇÁ constatou uma estação de tratamento desativada. Segundo relatos de moradores locais, a estação foi construída por volta do ano de 2010 para atender ao bairro de Papucaia, contudo, jamais funcionou (Figura 8).

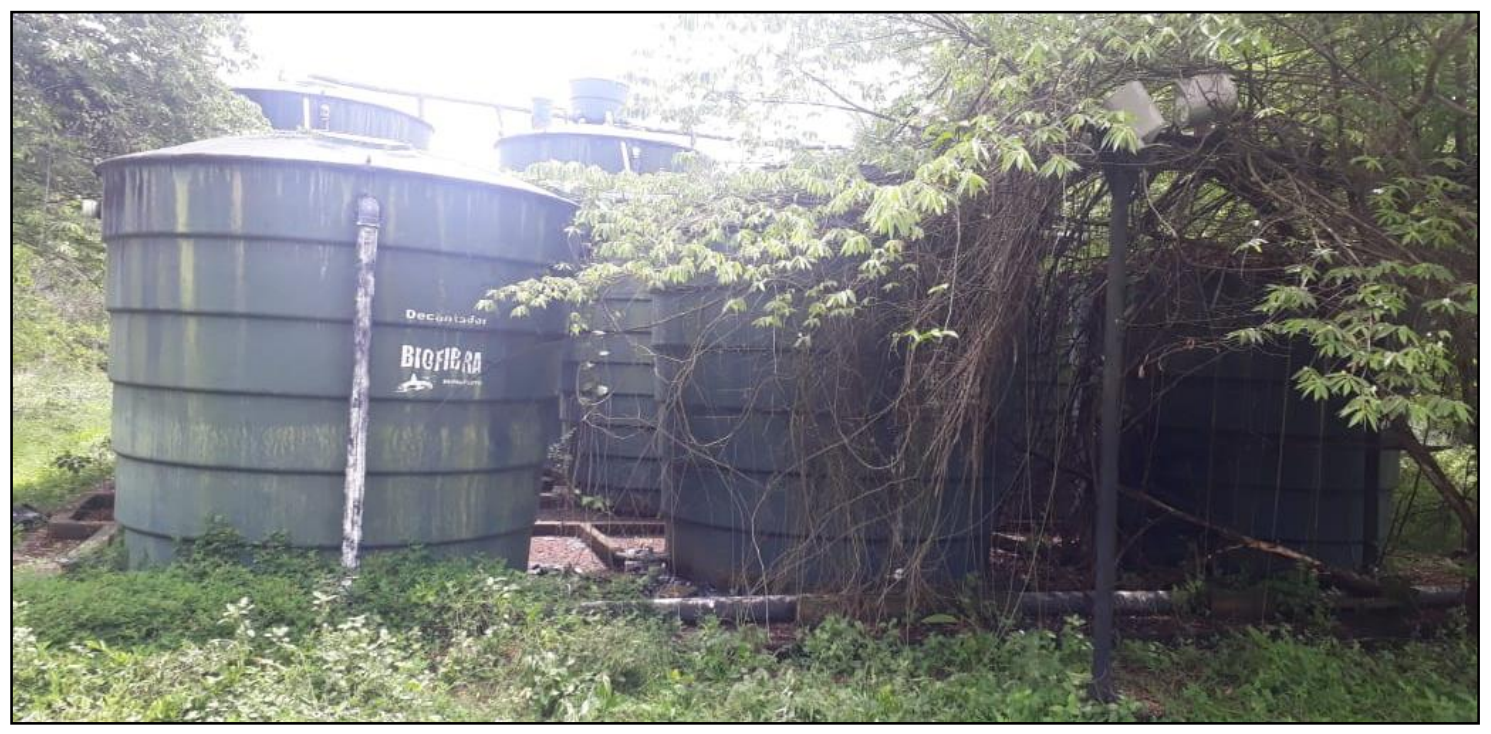

Figura 8. Vista parcial da estação abandonada (Fonte: Projeto UÇÁ).

De acordo com o Painel Saneamento Brasil, portal criado pelo Instituto Trata Brasil (2019) para disponibilizar informações sobre saneamento básico, foi possível fazer um panorama da situação do saneamento para Cachoeiras de Macacu. Os dados, referentes a 2018, mostram que 5.5\% da população não têm acesso à água tratada, o equivalente a 3.229 pessoas; $45.4 \%$ não possuem coleta de esgoto (aproximadamente 26.500 mil moradores). De acordo com Sistema Nacional de Informações sobre Saneamento (SNIS 2018), o município de Cachoeiras de Macacu, apesar de possuir uma autarquia municipal responsável pela água e esgoto, não possui estação de tratamento. Dessa forma, $100 \%$ do esgoto gerado no município são lançados sem tratamento no Rio Macacu.

O diagnóstico ambiental foi finalizado na porção a montante do centro de Cachoeiras de Macacu, onde as condições do rio melhoram substancialmente e os impactos antrópicos visíveis diminuem, em virtude da presença do Parque Estadual dos Três Picos. O Rio Macacu nasce no interior do parque e faz parte do Mosaico Central Fluminense, formando um contínuo florestal com o Parque Nacional da Serra dos Órgãos e com a Estação Ecológica Estadual do Paraíso, o que aumenta a sua importância como refúgio para inúmeras espécies da fauna e da flora, além de possuir diversas nascentes que formam importantes bacias hidrográficas de influência regional (INEA 2013). No interior do Parque, o Rio Macacu apresenta águas cristalinas e suas margens encontram-se muito preservadas por vegetação nativa da Floresta Ombrófila Densa (Figura 9).

\section{Propostas para correção dos problemas encontrados}

A falta de envolvimento da população com as ações ambientais é um fator que prejudica a conservação local. Dessa forma, observa-se a necessidade de campanhas voltadas para a sensibilização ambiental dos moradores do município como um todo, tendo em vista que, a vivência cotidiana muitas vezes mascara circunstâncias visíveis, mas não perceptíveis. Mesmo contemplando casos de agressões ao ambiente, os hábitos cotidianos concorrem para que a população muitas vezes não reflita sobre as consequências dos danos ambientais que ocorrem no Rio Macacu. Portanto, para a melhora da relação homem-natureza, é necessário realizar um 
trabalho com a comunidade, a fim de se obter uma sensibilização ambiental, mostrando-os a importância do ambiente onde vivem e que isso requer sobre eles certa responsabilidade.
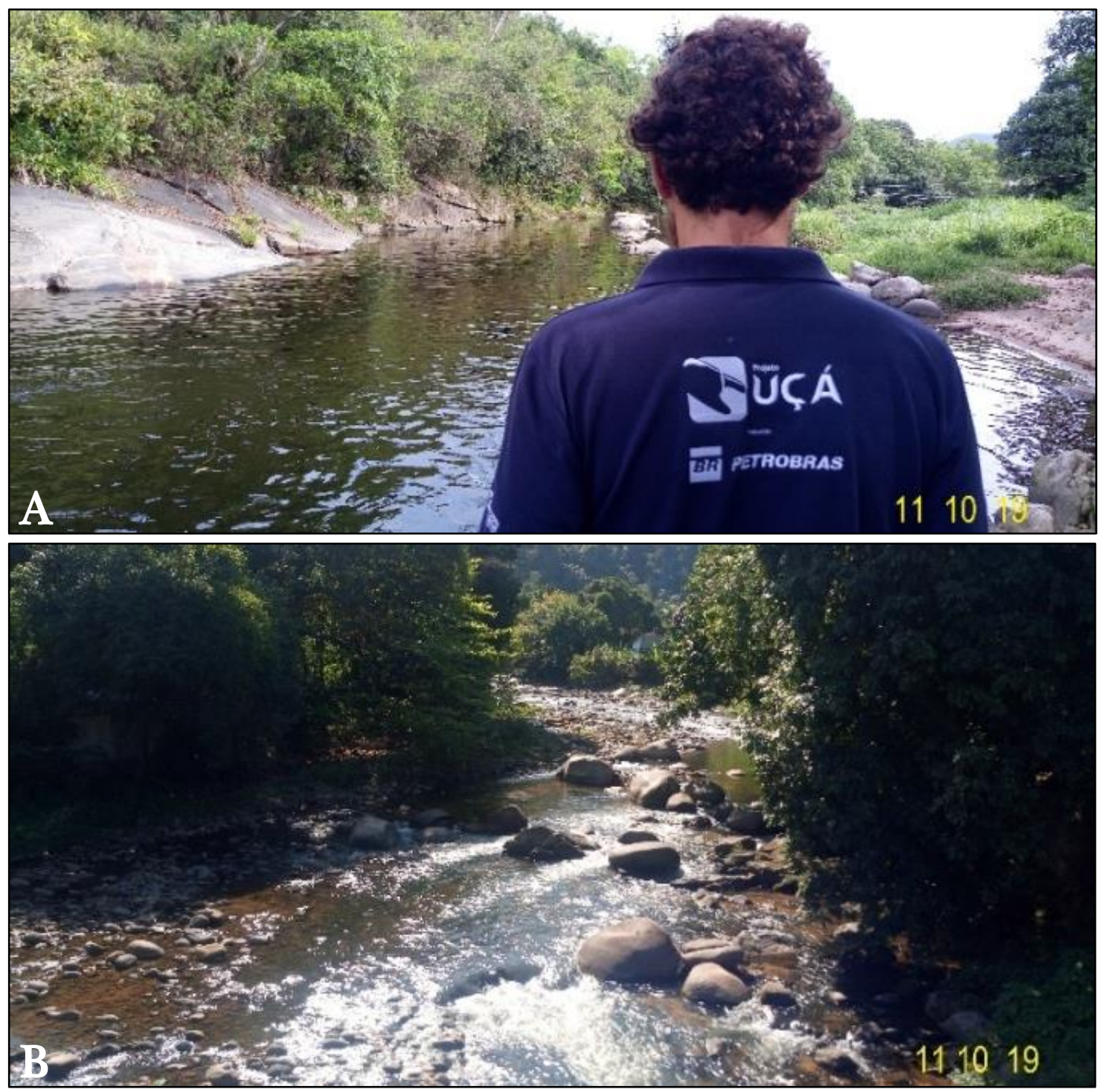

Figura 9. Rio Macacu no interior do Parque Estadual dos Três Picos: A-B. Diagnóstico do Rio Macacu, em sua porção localizada em ambiente preservado (Fonte das imagens: Projeto UÇÁ).

Para o Baixo Macacu, devem-se identificar os proprietários das terras localizadas às margens do rio para tentar estabelecer, juntamente com o Poder Público e instituições financiadoras, projetos de restauração florestal de toda a calha, como também o respeito aos limites da APP estabelecidos no Código Florestal (Brasil 2012). Salienta-se que áreas vegetadas ao longo do rio garantirão a proteção dos recursos hídricos, a integridade ecológica das áreas úmidas e o fluxo gênico entre remanescentes florestais, resultando em impactos positivos, inclusive, para o ecossistema de manguezal, que se faz presente em sua foz. Dessa forma, projetos de restauração florestal de mata ciliar é uma característica básica para melhorar a qualidade da água (Mello et al. 2018).

Para o Alto Macacu devem ser adotadas as seguintes medidas:

- Implementar de uma visão do meio urbano como organismo único, integrando visão ecológica e urbanística por meio do desenvolvimento de Programas de Educação Ambiental nas APPs, buscando soluções para estimular o contato com o rio, através de parcerias com associações de moradores e empresas; 
- Realização de mapeamento do perímetro urbano às margens do rio para elaboração de planos setorizados de requalificação urbana e ambiental, de modo a resolver a ocupação irregular da Faixa Marginal de Proteção, que impacta diretamente no equilíbrio entre vazão e drenagem, paisagem e abastecimento;

- Buscar soluções junto ao Poder Público para implantação de infraestrutura de saneamento e tratamento do esgoto doméstico, que constitui uma das principais fontes do problema de poluição do rio;

- Implantar, juntamente com a Prefeitura e associação de moradores, um projeto de reciclagem e coleta seletiva, uma vez que reduziria o lixo que é lançado ao rio e acaba tendo como destino os Manguezais da APA de Guapi-Mirim. Essa ação beneficiaria toda a região hidrográfica, pois o material seria reciclado, ao invés de ser levado ao aterro sanitário ou disposto de forma incorreta;

- Criação de atrativos econômicos e financeiros para propriedades privadas que respeitam a legislação ambiental, localizadas ao longo do rio, ajudando a fomentar o turismo e a economia local;

- Buscar implementação de uma nova concepção de APPs na margem do curso d'água, com áreas públicas de lazer e convivência social, equipamento de saneamento e arborização, tratando, assim, da bacia hidrográfica urbana.

\section{Considerações finais}

Estudos relacionados à degradação ambiental em bacias hidrográficas são de vital importância para o entendimento de aspectos da relação sociedade-natureza, constituindo um importante instrumento de planejamento, que tenha por meta, a qualidade de vida e a sustentabilidade ambiental. Este trabalho vem como instrumento norteador de políticas públicas para qualificar e quantificar a realidade existente na região da Bacia Hidrográfica do Rio Macacu - RJ em relação ao seu grau de degradação. Com isso, será possível estabelecer metas de planejamento de uso dos recursos hídricos nos municípios abrangidos pela área estudada, equalizando a problemática e evitando a degradação de seus mananciais. Medidas como ordenamento urbano, coleta e tratamento de esgoto, instalação de estações de tratamento e a restauração florestal das margens são atividades essenciais para melhoria da qualidade das águas do Rio Macacu, o que terá como consequência a melhoria da qualidade das águas da Baía de Guanabara. Dessa forma, é de grande importância que as ações acima descritas sejam amparadas pelo poder público local ou estadual, de forma a melhorar a qualidade de vida de milhares de pessoas.

\section{Agradecimentos}

Os autores agradecem à Associação de Moradores e Amigos de Papucaia pelo apoio logístico, ao Patrocínio da Petrobrás, por meio do Programa Petrobras Socioambiental e aos revisores deste manuscrito pelas valiosas contribuições.

\section{Referências}

Amador E.S. (2012) Baía de Guanabara e ecossistemas periféricos: homem e natureza. Rio de Janeiro: edição do Autor. 539 p.

Andrade L.M.S. \& Romero M.A.B. (2006) A importância das áreas ambientalmente protegidas nas cidades (p. 1-20). In: XI Encontro Nacional da Associação Nacional de Pós-Graduação e Pesquisa em Planejamento Urbano e Regional. Volume 5. Salvador: ANPUR.

Bertoni J. \& Lombardi Neto F. (2010) Conservação do solo. $7^{\circ}$ edição. São Paulo: Ícone. 355 p.

Brasil (2001) Ministério da Agricultura. Comunicado Tecnico 69. Capim-massai (Panicum maximum CV. Massai): alternativa para diversificação de pastagens. Campo Grande: MAPA. $5 \mathrm{p}$.

Brasil (2012) Lei No 12.651, de 25 de maio de 2012. Brasília: MMA.

Carvalho D.F., Montebeller C.A., Franco E.M., Valcarcel R. \& Bertol I. (2005) Padrões de precipitação e índices de erosividade para as e índices de erosividade para as chuvas de 
Seropédica e Nova Friburgo, RJ. Revista Brasileira de Engenharia Agrícola e Ambiental, 9(1): 7 14. https://doi.org/10.1590/S1415-43662005000100002

Casseti V. (1983) Algumas considerações a respeito dos fenômenos pluvio-erosivos em Goiânia Goiás. Boletim Goiano de Geografia, 3: 161-180. https://doi.org/10.5216/bgg.v3i1.4278

Castro M.N., Castro R.M. \& Souza P.C. (2013) A importância da Mata Ciliar no Contexto da Conservação do Solo. Revista Eletrônica de Educação da Faculdade Araguaia, 4(4): 230-241.

Colpo K.D., Brasil M.T. \& Camargo B.V. (2009) Macroinvertebrados bentônicos como indicadores do impacto ambiental promovido pelos efluentes de áreas orizícolas e pelos de origem urbana/industrial. Ciência Rural, 39(7): 2087-2092. https://doi.org/10.1590/S0103-84782009005000161

COPASA - Companhia de Saneamento de Minas Gerais (2015) Programa Chuá: Educação sanitária ambiental. Belo Horizonte. Disponível em: http://jornalarte3.blogspot. com/2017/09/ programa-chua-de-educacao-sanitaria-e.html (acessado em 05/05/2020)

Coutinho L.M., Zanetti S.S., Cecílio R.A., Garcia G.O. \& Xavier A.C. (2013) Usos da Terra e Áreas de Preservação Permanente (APP) na Bacia do Rio da Prata, Castelo-ES. Floresta e Ambiente, 20(4): 425-434. https://doi.org/10.4322/floram.2013.043

Ecologus-Agrar (2003) Plano Diretor de Recursos Hídricos da Região Hidrográfica da Baía de Guanabara. Relatório final - síntese. Rio de Janeiro: Consórcio Ecologus-Agrar. 203 p.

Galindo E.F. (2004) A intersetorialidade como requisito para construção deuma Cidade Saudável: política de Saneamento e de Saúde no Recife (gestão 2001-2004) - Estudo de Caso. Dissertação (Programa de Pós-Graduação em Desenvolvimento Urbano). Universidade Federal de Pernambuco, Recife, Pernambuco.

Gomes E.C.F., Jesus E.N., Oliveira N.N.O., Gonçalves Júnior L., Cabral F.G.S. \& Resende M.S.R. (2018) A nova legislação ambiental brasileira e seus efeitos sobre a reestruturação de nascentes e remanescentes florestais. Pesquisa Florestal Brasileira, 38: e201601309. https://doi.org/10.4336/2018.pfb.38e201601309

Heller L. \& Möller L.M. (1995) Saneamento e saúde pública (p. 51-61). In: Barros R.T.V., Chernicharo C.A.L., Heller L. \& von Sperling M. (Orgs) Manual de saneamento e proteção ambiental para os municípios. Volume 2. Belo Horizonte: Escola de Engenharia da UFMG. $221 \mathrm{p}$.

Hora A.F., Hwa C.S. \& Hora M.A.G.M. (2010) Planejamento Estratégico da Região Hidrográfica dos Rios Guapi-Macacu e Caceribu-Macacu. Niterói: UFF/FEC. 544 p.

IBAMA (2002) Portaria $n^{0} 124 / 2002$. Dispõe sobre proibição relativa à captura, manutenção em cativeiro, transporte, beneficiamento, industrialização, armazenamento e comercialização da espécie Ucides cordatus. Brasília: IBAMA. Disponível em: https://www.normasbrasil.com.br/no rma/portaria-124-2002_183518.html (acessado em 02/04/2020).

ICMBio - Instituto Chico Mendes de Conservação da Biodiversidade. (2020) https://www.icmbio.g ov.br/apaguapimirim (acessado em 15/04/2020).

]INEA - Instituto Estadual do Ambiente (2013) Parque Estadual dos Três Picos: plano de manejo/resumo executivo/Instituto Estadual do Ambiente. Rio de Janeiro: INEA. Disponível em: http://www.inea.rj.gov.br/cs/groups/public/documents/document/zwew/mde5/ edisp/inea0 019756.pdf (acessado em 15/04/2020).

Kominoski J.S., John J.S., Shah J.J.F., Canhoto C., Fischer D.G., Giling D.P., González E., Griffiths N.A., Larrañaga A., LeRoy C.J., Mineau M.M., McElarney Y.R., Shirley S.M., Swan C.M. \& Tiegs S.D. (2013) Forescasting functional implications of global changes in riparian plant communities. Frontiers in Ecology and the Environment, 11(8): 423-432. https://doi.org/10.1890/120056

Lima W.P. (2008) Hidrologia florestal aplicada ao manejo de bacias hidrográficas. Piracicaba: ESALQ. 242 p.

Lima W.P. \& Zakia M.J.B. (2004) Hidrologia de matas ciliares (p. 34-44). In: Rodrigues R.R. \& Leitão Filho H.F. (Eds). $2^{\circ}$ edição. Matas Ciliares: Conservação e recuperação. São Paulo: EDUSP/FAPESP. 320 p.

Lyra B.U. \& Rigo D. (2019) Deforestation impact on discharge regime in the Doce River Basin. Revista Ambiente \& Água, 14(4): e2370. https://doi.org/10.4136/ambi-agua.2370 
Maia A.P.A. (2002) Gestão de recursos hídricos em Pernambuco: o comitê de Bacia Hidrográfica do Rio Pirapama. Dissertação (Programa de Pós-Graduação em Gestão e Políticas Ambientais). Universidade Federal de Pernambuco, Recife, Pernambuco.

Mantoani M.C., Andrade G.R., Cavalheiro A.L. \& Torezan J.M.D. (2012) Impacts of Panicum maximum Jacq. invasion and its manual weeding on the wood plant regeneration in the understory of a restoration site. Semina: Ciências Biológicas e da Saúde, 33(1): 97-110.

Martins C.R., Leite L.L. \& Haridasan M. (2004) Capim - gordura (Melinis minutiflora P. Beauv.), uma gramínea exótica que compromete a recuperação de áreas degradadas em unidades de conservação. Revista Árvore, 28(5): 739-747. https://doi.org/10.1590/S0100-67622004000500014

Mello K., Valente R.A., Randhir T.O., Santos A.C.A. \& Vettorazzi C.A. (2018) Effects of land use and land cover on water quality of low-order streams in Southeastern Brazil: Watershed versus riparian zone. Catena, 167: 130-138. https://doi.org/10.1016/j.catena.2018.04.027

Mielke E.C., Negrelle R.R.B., Cuquel F.L. \& Lima W.P. (2015) Espécies exóticas invasoras arbóreas no parque da Barreirinha em Curitiba: registro e implicações. Ciência Florestal, 25(2): 327 336. https://doi.org/10.5902/1980509818451

Morgan R.P.C. (2005) Soil erosion and conservation. $3^{\circ}$ edition. Hoboken: Wiley-Blackwell. 304 p.

Pereira B.W.F., Maciel M.N.M., Oliveira F.A., Alves M.A.M.S., Ribeiro A.M., Ferreira B.M. \& Ribeiro E.G.P. (2016) Uso da terra e degradação na qualidade da água na bacia hidrográfica do rio Peixe-Boi, PA, Brasil. Revista Ambiente \& Água, 11(2): 472-485. https://doi.org/10.4136/1980-993X

Pires E.V.R., Silva R.A., Izippato F.J. \& Mirandola P.H. (2012) Geoprocessamento Aplicado a análise do uso e ocupação da terra para fins de planejamento ambiental na bacia hidrográfica do Córrego Prata - Três Lagoas (MS). Revista Geonorte, 2(4): 1528-1538.

Roberto D.M. (2009) Diagnóstico da hidrografia - Estação Ecológica da Guanabara e Região. Rio de Janeiro: Ecomek. 22 p.

Salamene S., Francelino M.R., Valcarcel R., Lani J.L. \& Sá M.M.F. (2011) Estratificação e caracterização ambiental da área de preservação permanente do rio Guandu/RJ. Revista Árvore, 35(2): 221-231. https://doi.org/10.1590/S0100-67622011000200007

Santos E.C.A., Araujo L.E. \& Marcelino A.S. (2015) Análise climática da Bacia Hidrográfica do Rio Mamanguape. Revista Brasileira de Engenharia Agrícola e Ambiental, 19(1): 9-14. http://dx.doi.org/10.1590/18071929/agriambi.v19n1p9-14

Silva V.A. \& Espiridião F. (2017) Saneamento básico e seus impactos na mortalidade infantil e no desenvolvimento econômico da Região Nordeste. Scientia Plena, 13(10): 1-7. https://dx.doi.org/10.14808/sci.plena.2017.109905

Silva V.A., Moreau M.S., Moreau A.M.S.S. \& Rego N.A.C (2011) Uso da terra e perda de solo na Bacia Hidrográfica do Rio Colônia, Bahia. Revista Brasileira de Engenharia Agrícola e Ambiental, 15(3): 310-315. https://doi.org/10.1590/S1415-43662011000300013

SNIS - Sistema Nacional de Informações sobre Saneamento (2018) Disponível em: http://www.snis.gov.br/diagnostico-anual-agua-e-esgotos/diagnostico-dos-servicos-de-agua-eesgotos-2018 (Acessado em 12/05/2020).

Thomaz E.L. \& Dias W.A. (2007) Influência do pastoreio na mudança física do solo em margens de canal fluvial. Relatório de iniciação científica. UNICENTRO: Guarapuava.

Thomaz E.L. \& Dias W.A. (2009) Bioerosão - Evolução do rebanho bovino brasileiro e implicação nos processos geomorfológicos. Revista Brasileira de Geomorfologia, 10(2): 3-11.

Instituto Trata Brasil (2019) Principais Estatísticas. Disponível em: http://www.tratabrasil.o rg.br/saneamento/principais-estatisticas/no-brasil/esgoto (Acesso em 10/05/2020).

Tucci C.E.M. \& Clarke R.T. (1997) Impacto das mudanças da cobertura vegetal no escoamento: Revisão. Revista Brasileira de Recursos Hídricos, 2(1): 135-152. https://doi.org/10.21168/rbrh.v2n1.p135-152

Valcarcel R. \& D’alterio C.F.V. (1998) Medidas físico-biológicas de recuperação de áreas degradadas: avaliação das modificações edáficas e fitossociológicas. Floresta e Ambiente, 5(1): 68-88. 
Vanzela L.S., Hernandez F.B.T. \& Franco R.A.M. (2010) Influência do uso e ocupação do solo nos recursos hídricos do Córrego Três Barras, Marinópolis. Revista Brasileira de Engenharia Agrícola e Ambiental, 14(1): 55-64. https://doi.org/10.1590/S1415-43662010000100008

Zanchetta D. \& Diniz F. (2006) Estudo da contaminação biológica por Pinus spp. em três diferentes áreas na Estação Ecológica de Itirapina - SP. Revista do Instituto Florestal, 18: 1-14. 